\title{
Culture-switching in different worlds: Young children's transition experiences
}

\author{
Beverly Fluckiger \\ Griffith University
}

THE CONSTRUCTS OF 'THREE WORLDS' and culture-switching were developed during a longitudinal study of the literacy experiences of a small group of culturally diverse children in Australia who encountered differing social and cultural contexts as they were transitioning from preschool to Year 1. Drawing on sociocultural perspectives and using a case study design, the report examines the ways in which five children negotiated culture, literacy, and schooling at home and in the classroom. The study establishes sufficient evidential warrant for further investigation into the nature and dimensions of world-building and culture-switching that seemingly characterise such literacy experiences. It may also provide insights for teachers of young, culturally diverse children starting school.

\section{Introduction}

The importance of early childhood education in preparing children for their future is broadly acknowledged. This means early childhood has a place on political, academic and community agendas and in state and Federal Government plans to 'bridge gaps' and enhance success in the early years of school (Simpson, 2009). Accordingly, assumptions about the dynamic and diverse mix of linguistic, cultural and religious backgrounds represented in Australian classrooms need to be challenged.

Ashton, Woodrow, Johnston, Wangmann, Singh and James (2008) attributed children's success at school to the congruence between the practices of home and school, while identifying differences in values, skills and learning styles-described as cultural dissonance-as inhibiting success. These claims are supported by studies that reveal children from minority cultures generally do not achieve the same success in literacy learning as children from dominant cultures (Purcell-Gates, 1993). Freeman and Bochner (2008) attempted to explain the difference by maintaining that teachers expect minority children to have already developed literacy skills and knowledge similar to children of the dominant culture and through similar experiences. As a result, minority children are left to cope with linguistic and cultural differences on their own, struggling to negotiate between home and school without sufficient assistance (Heath, 1982). A second explanation is that teachers, in attempts to take account of the cultural diversity in their classrooms, may make unhelpful assumptions about children's knowledge, experiences and practices, based on stereotypical perceptions of cultural traits (Rogoff \& Angelillo, 2002).

However, some minority children, despite cultural and linguistic differences, do adapt successfully to school environments and develop literacy knowledge and skills apace with their peers. An attempt to explain the successful adaptation of such children could be made in terms of their skills of border-crossing.

Border-crossing is a metaphor first used by Anzaldua (1987) to describe the difficulties encountered by those traversing the divides between societal groups. While the notion of cultural borders may seem authentic and real from a societal perspective that views a culture as a bounded system, separable and distinguishable from others, the power of the cultural border rhetoric seems to lose its potency when the focus switches from a society (or group) to individuals (Chang, 1999). As outlined in the present study, individuals build a unique and personal cultural identity through a process of assimilation and accommodation of aspects of the diverse cultures that form their experiences. The metaphor of border-crossing is inadequate to describe this process. Therefore, 
alternative ways of describing the cultural identity building of individuals are needed.

In the present study, a construct of three worlds was used to describe the very different experiences the five children encountered at home, preschool and in Year 1. World-building was the term used to describe the process the children engaged in to construct their individual cultural identities, and culture-switching was coined to describe the purposeful actions of mixing, transferring and borrowing that children appeared to have undertaken, in order to have their needs met and to achieve success.

\section{Background and methodology}

The study examines the literacy experiences of a small, culturally diverse group of children (five girls), and the environments in which these experiences occurred. The study aimed to assist in clarifying how young children negotiate culture, literacy, and schooling. The results of the study were intended to assist teachers in developing an understanding of the rich cultural diversity present within classrooms and the benefits of acknowledging this as a resource that can help support children's literacy learning.

The fine-grained study took place during the last three months of the preschool year and during the first six months of some of the children's first year of formal schooling. It originally involved detailed case studies of five girls who attended the same preschool: Grace, Jeva, Lia, Kari and Zara (these names are pseudonyms). Their families came from Korea, Bangladesh, Indonesia, Japan and Australia respectively.

Using multiple strategies, the data was collected in the children's homes, at a state-run preschool, and then in a Year 1 state school classroom that three of the children later attended. The strategies employed included continuous observation of writing activities in three settings (videotaped in preschool and the Year 1 classroom), interviews with parents and teachers, regular audiotaped telephone conversations with parents about writing experiences that occurred in the home, and the collection of writing samples.

Researchers attempting to describe and understand aspects of early childhood often favour qualitative approaches that accommodate the complexity and diversity of the experiences of others (MacNaughton, Rolfe \& Siraj-Blatchford, 2001). The value of a qualitative approach was clearly relevant to the present study, in which enhanced understandings were sought about the relationships between literacy experiences at home, at school, and across cultures. Approaches used in this study are consistent with contemporary, qualitative research whose strength lies in the production of fine-grained data (Merriam, 1988). Data in this study was analysed using grounded theory, and reported using multiple and diverse confirmatory strategies.
The study consisted of five qualitative case studies used to explore the processes and dynamics of minority children's literacy experiences and to gain an in-depth understanding of their contexts and meanings. Qualitative case studies do not seek to make generalisations, but rather to honour the specificities of the cases reported. Case studies are characterised by the engagement of empathy and the discovery of new relationships, concepts and understandings, rather than verification of predetermined hypotheses (Strauss \& Corbin, 1998). As Merriam (1988) explained: 'the interest is in the process rather than outcomes, in context rather than a specific variable, in discovery rather than confirmation' (p. xii).

\section{Analysis}

The data was analysed using a constant-comparison process as employed in the grounded theory method. This method has been widely accepted and adapted among qualitative researchers since its inception and, despite internal debate, continues to be used extensively (Greckhamer \& Koro-Ljungberg, 2005). It provides a set of procedures and analytical steps to analyse data that is grounded in the context of the study and seeks to generate theory. The steps taken in this study were similar to descriptions by Charmaz (2002) that included: (a) simultaneous data collection and analysis; (b) pursuit of emergent themes through early data analysis; (c) discovery of basic social processes within the data; (d) inductive construction of abstract categories that explain and synthesise these processes; (e) sampling to refine the categories through comparative processes; and ( $f$ ) integration of categories into a theoretical framework that specifies causes, conditions and consequences of the processes studied.

First, the audiotapes of telephone conversations conducted fortnightly with parents were transcribed and read repeatedly in conjunction with the observation field notes to identify features of the home writing experiences. Writing samples or products of the home writing experiences were studied, in conjunction with the transcripts and field notes, in order that the skills and knowledge described by the parents could be examined. Background information provided by the parents during the initial interview was also considered when identifying crucially important features.

Second, the videotapes of the children's preschool writing experiences were analysed in a similar way to the audiotaped conversations. These tapes were transcribed and viewed repeatedly and demonstrably salient features of experiences were identified, using the raw data as examples to illustrate them. Writing samples or products of preschool activities were studied in conjunction with these transcripts. Background information provided by the preschool teacher during the initial interview was also considered when identifying their features. These features 
were compared, contrasted and grouped together to form categories (later referred to as characteristics). Children's individual experiences were compared, and then comparisons made amongst the children. Then the process was repeated with the data gathered on writing experiences in Year 1. The coding process was explained to a co-rater who replicated the coding process to establish the reliability of the categorisation. The co-rater undertook independent coding of 10 per cent of the transcripts of data from the three settings (home, preschool and Year 1) and an inter-reliability of 98.4 per cent was achieved. The coding process was determined to be extremely reliable.

Finally, with reference to accompanying features and examples, categories were compared and contrasted amongst children and between settings, and further categorised to form the dimensions of writing experiences. Throughout the process of analysis, concepts and relationships were deduced from the data. The final theory that emerged was derived from the data through close attention to the features, characteristics and dimensions of writing experiences.

\section{Participants: The children and their families}

The five girls who were the focus of the study attended the same preschool in an inner suburb of a large Australian city. The children were chosen for the study because: a) their parents were willing to participate in the study; b) their parents planned to remain in Australia for the duration of the study; c) they spoke their heritage language at home; and d) their families represented a variety of cultural backgrounds. Five girls and their families from the 25 children in the class met these criteria and all were included in the study.

The backgrounds of the five families, seen as middle-class because of their tertiary education and socioeconomic status, varied markedly. Jeva's family were immigrants from Bangladesh. Despite limited English, they had left family and friends to provide a brighter future for Jeva and her older sister in Australia. Jeva's mother experienced constant homesickness in Australia, exacerbated when the father returned to Bangladesh for months at a time to work as a scientist. This meant Jeva's mother, with limited English, cared for the family alone during the father's absences.

Grace was the youngest of three children in her Korean family. Her mother worked at night, washing up in restaurants to support the family while the father studied to become a minister of religion. Strict study routines had been established for Grace and her brothers. When the boys did their homework, Grace completed literacy activities in workbooks purchased from the local newsagent and Sunday School homework activities. She was not praised for her efforts as her mother believed that praise inhibited a child's diligence and willingness to work hard.
Kari was the daughter of a Japanese government representative living in Australia. She lived in a large, luxurious home on acreage and participated in many organised after-school activities with her older brother. At home, Kari was reluctant to stay in her bedroom, which was distant from other living areas in the house. When she commenced Year 1, a tutor was engaged to give her English lessons and assist with her homework.

Lia was the middle child of a large Indonesian family who lived in a small two-bedroom flat. Her family planned to return to Indonesia when the father completed his studies to become a town planner. Lia and her older siblings spent their free time playing on the street, as their mother was busy caring for the younger children and there was limited space inside. Her parents believed that Lia would just become literate when she started formal schooling and that accordingly, as parents, they had no role in this process.

Zara was the Australian child in the study. She lived with her mother and brother for several days each week and with her father for the remaining days. Her mother embedded literacy activities in many of the experiences she planned and engaged in with Zara.

\section{Three worlds}

\section{The home world}

The home literacy experiences were embedded within the social fabric of family life. They incorporated cultural values, attitudes and beliefs that were strenuously maintained so as to ensure continued understanding and preservation of family ties and cultural heritage. These included maintaining heritage language at home, religious rituals, correspondence with relatives overseas, and participation in cultural celebrations.

\section{Nature of home literacy activities}

The nature and frequency of planned activities and parent participation varied. For example, Grace, Zara and Jeva's parents undertook literacy activities frequently. Zara's experiences were negotiated with her mother, while Grace and Jeva's experiences were highly structured and didactic or transmissive in nature. For example, Grace was set written tasks in workbooks to complete, which her mother supervised and then corrected.

Kari and Lia's parents nor did not plan or engage with their children in literacy activities, as they did not believe they had any role to play in teaching their children to be literate. Instead, they believed their children should and would learn literacy at school. As Taylor (1983) also found, memories of their own unsupported literacy experiences likely led to the minimal ways these parents interacted with their children.

The nature and frequency of literacy conversations and interactions conformed to social conventions inherent in 
traditional family practices. For example, in Jeva's family, the father initiated literacy activities each evening after dinner. The family gathered in the living room, where Jeva sat on the floor and recited and recorded the Bangla alphabet and numbers to 100, before repeating the process in English. This was reminiscent of the way her parents had rotelearned the Koran. Her father also mediated conversations that followed established patterns and rules of respect and authority. For example, Jeva always obeyed her father's instructions without question and demonstrated respect in her demeanour. She observed and listened to her parents' conversations but did not participate as a conversational partner unless invited. When she did participate, her role was not an equal one.

Lia and Kari initiated conversations with their parents, but opportunities to do so were limited owing to physical arrangements. In Kari's home, children were not permitted into the study. This was where the father worked, and the mother frequently conversed with him there. Lia spent most of her time outside playing with siblings because of limited space inside, and therefore few opportunities arose for conversations with parents. In contrast, Zara initiated frequent conversations with her parents, often directing conversations and even dominating interactions, at times interrupting and disagreeing with her mother.

The materials available to the children for literacy activities at home varied markedly. Grace, Kari and Zara were provided with a plethora of resources while Jeva and Lia had few. However, the provision of materials did not appear to impact on the engagement of children in literacy experiences. Lia, for example, constructed opportunities for literacy and utilised environmental resources in creative ways, demonstrating agency in her own self-directed literacy learning and her ability to shape her environment. This may be attributed to the literacy practices and environmental print she encountered both within and beyond her home. Her father was often studying in the bedroom, and Lia interrupted his work frequently by climbing on his knee to demand his attention. She questioned him about his work, and named and typed the letters that she knew on the computer keyboard.

\section{Home literacy values and beliefs}

Despite the differences outlined above, families had some values, attitudes and beliefs in common. These shared values, expressed by parents, included recognition of the importance of education, the need for children to achieve highly and be happy at school, and the importance of hard work. These beliefs and values are consistent with those identified by Goldenberg (1987), who suggests that members of differing cultural groups may have more shared than different values and are also typical of middleclasses anywhere in the world.

Laosa (1980) suggested, along with others (Lareau, 2002; Lareau, 2003), that parents' social class and educational backgrounds are dimensions of culture that carry more influence than others in relation to children's early learning opportunities. The shared values of the families in this study are typical of educated middle-classes and are recognised as values that have a positive influence on children's adaptation to school (Goldenberg, 1987). Apart from the value attributed to learning and education, and the expectation that their children would be successful, parents' openness to acknowledge others' ways of doing things fostered in the children a willingness to learn from others. For example, Grace's parents had accepted that the main activity of preschool was play, despite their belief that learning was a serious and disciplined activity.

Similarly, the practices the children and their families engaged in at home reflected and promoted a system of definitions of themselves and their worlds (Bourdieu, 1990). For example, Grace identified as Korean despite having been born in Australia. The Korean language, food, games, and ways of doing things that comprised her world at home reinforced that heritage identity.

\section{Active participation at home}

Children were identified in this study as being active participants in their home world. Their actions and interactions with people, objects and symbols contributed to the shaping of their own experiences and that of their home environment. For example, as Jeva's confidence with writing grew at school, she rejected instruction and assistance from her mother. Instead, she directed her mother to find or draw pictures with the letter sounds she was practising. Rogoff (2003) described the relationship between an individual and their culture as one of mutual constitution, which suggests dynamic interactions rather than causal influence and which promotes a view of culture as undergoing continual change, rather than being static. Thus Jeva's increasing confidence and independence resulted in a shift in the roles and nature of the literacy experiences at home.

The dynamic nature of children's actions and interactions that contributed to shaping their experiences and home world was evident in roles they adopted and their interactions and behaviour. For example, the paucity of literacy materials in Lia's home did not limit her, but led to inventiveness in engaging in literacy experiences. She utilised a variety of surfaces to write on, including scraps of paper and, much to her parents' dismay, the walls of the apartment. Similarly, she created activities for herself, using print on packets and tins, calendars, and advertising that came in the junk mail, and demanded answers to her literacy-related questions. All five children displayed a range of actions and behaviours that demonstrated values and interests of their own, and an ability to make decisions and act on their own behalf.

The decisions the children made and actions they took shaped their own experiences and also shaped their home world. Some parents depended on their children's knowledge of Australian culture to assist them. For 
example, in the absence of her father, Jeva became a translator for her mother when shopping, a negotiator in business transactions, and a mediator explaining the nuances and differences in practices between cultures. Jeva interacted with a range of adults in the community and adopted roles not usually expected of Australian children. Some children became, in effect, cultural brokers or go-betweens, advocating for their family and negotiating between various cultures on a regular basis. These experiences provided such children with opportunities for conversational practice and to adopt roles outside the constraints of social conventions of their culture.

The literacy knowledge and skills, cultural practices and dispositions that the children acquired and used to operate in their home environment constituted conceptual resources they could draw on. These resources were acquired through dynamic interactions with their home environment that shaped both their literacy experiences and cultural environment. In the following section, children's acquisitions of resources in the preschool environment are examined.

\section{The world of preschool}

Preschool was very different from children's home worlds. The teacher encouraged ways of operating that reflected mainstream Australian culture. For example, parents and their children were encouraged to speak English in the classroom and adopt Australian social conventions and practices exclusively. Some social practices emphasised were greeting people, looking at people when speaking to them, and waiting to speak without interrupting. The teacher believed that children needed English language and customs for success at school and therefore adopted a single cultural narrative. As Bourdieu's (1990) theory of social reproduction and cultural capital suggests, and as her practice confirmed, only the culture of the dominant class is valued and rewarded in monocultural educational systems. As a passive functionary of the system, the teacher shaped the world of preschool to reflect the dominant monoculture and its system values and rewarded only those who acted in accordance with the norms of this world, not the three worlds.

\section{Nature of literacy activities in preschool}

Culturally diverse families acknowledged aspects of the dominant culture (while preserving their own) and encouraged their children to adopt preschool practices. These included speaking English at preschool, negotiating their participation in activities, and demonstrating independence. In this way the children acquired the cultural capital perceived as requisite for educational success at preschool while maintaining the practices and beliefs of their heritage culture at home. A second benefit was that parents developed knowledge of Australian culture through their children's experiences, and this shaped their home world.
The preschool teacher believed that children developed literacy knowledge in the early years by engaging with literacy resources in play. Therefore, she included calendars and diaries, eye charts and other literacy-related props to be incorporated into their play in the 'hospital' set up in the home corner. Her children were encouraged to interact socially with one another at preschool, but opportunities for engaging in extended conversations and interacting as conversational partners with adults, as some did at home, were limited. Instead, children observed, initiated and participated in conversations and interactions with one another during play. The parents did not value play as an educative process in the way the teacher did. While most parents viewed play as a social activity unrelated to the formal literacy learning of their children, they commented on its value for the development of language and friendships with peers.

\section{Preschool literacy values and beliefs}

Many of the preschool teacher's values, attitudes and beliefs differed from those of the parents, especially in relation to how children learn to be literate, the educative role of teachers in the literacy process, and what constituted accepted language practices and social conventions. Despite this, the children acquired resources requisite for successful participation in learning at preschool. These included the independent use of materials and resources, accepted social practices, and the ability to negotiate activities. The acquisition of appropriate resources was seen as a process that children went through, motivated by the need for effective behaviour and involving the use of a variety of strategies and tactics to achieve objectives.

\section{Active participation in preschool}

In coming to terms with appropriate preschool practices and using them effectively to achieve such objectives, the children employed a variety of strategies. They mixed ways of doing things at home with preschool ways of doing things. For example, role-play in home corner was a blend of culturally appropriate practices and preschool ways of doing things. At times, children transferred home expectations to preschool. For example, Jeva and Grace expected that writing would be a priority at preschool as it was at home, and continued to incorporate writing into their activities and showed the adult what they had done.

At other times, the children tried out behaviours and adjusted or discarded them in response to the reactions of others. For example, many of Lia's first attempts to negotiate membership of a group were unsuccessful, particularly when she criticised participants or seized the resources being used in the activity. Other tactics she tried were standing at the edge of an activity area and then insinuating herself into the activity. For example, she tried to join several children completing a jigsaw puzzle by looking over their shoulders and smiling and laughing with them and then reaching out to choose a puzzle piece. 
The container was quickly moved away by another child so that Lia could not reach. Over time, Lia developed a variety of successful strategies to gain access to activities. One was to ask questions or seek help from others. For example, when playing 'school', she assumed a seat and asked the child who was playing teacher: Is this where you write your name? By recognising the child in the teaching role and asking a question, she had ensconced herself successfully in the game.

On other occasions, the children experimented with known preschool practices and adopted tactics that led to the achievement of their objectives. For example, in order to limit or reject participants, they often applied the preschool rule that only four children could participate in an activity. Similarly, children invoked the rule to gain entry when there were fewer than four in an activity.

The roles and behaviours the children adopted contributed to the shaping of experiences and the preschool environment in similar ways that actions and interactions shaped experiences and the environment at home. The examples outlined above demonstrate the active way that children engaged in acquiring knowledge and skills about literary and cultural practices valued at preschool. The dynamic nature of their actions and interactions in mixing, transferring, trying out and adapting practices from others contributed to the shaping of the preschool environment. For example, Grace tried on a number of occasions to get the teacher to respond to her attempts at writing. On one of these occasions, she asked if the teacher was able to read her writing, thus inviting the teacher to collaborate in her writing attempt. The active nature of children in making decisions and applying appropriate behaviours to suit the environment in which they found themselves, and in shaping the school environment through these actions, is examined further in the following section.

\section{The other world of the Year 1 classroom}

In the Year 1 classroom, the teacher regarded diversity as an asset rather than a liability. She viewed the differences between home and school practices as alternate beliefs and legitimate forms of practice. For example, when this teacher discussed the use of pictures to assist reading, Grace revealed that her mother covered up the pictures in her take-home reader to ensure she read the words. The teacher responded that she had noticed Grace knew many words.

\section{Nature of literacy activities in Year 1}

The experiences each child brought to the class were recognised as unique and shared and discussed. Jeva's participation in cultural celebrations of Bangla Independence Day, for example, provoked wider discussion of special celebrations. These opportunities for listening, responding and valuing the experiences, thoughts and ideas of others created a learning community where children actively learned from others.

The children established themselves as competent community members and demonstrated independent decision making. For example, they used writing sessions to provide information and share their knowledge with others, both verbally and through their writing. As knowledge of the writing process increased, they used it to help others. They pointed out when words were spelt incorrectly, or where spaces between words were forgotten. Over time, the children developed confidence about their skills and abilities, together with a robust sense of self-esteem and responsibility. They demonstrated a willingness to share their knowledge and ideas, especially in relation to writing.

\section{Literacy values and beliefs in Year 1}

The teacher attempted to build on the rich diversity of resources the children brought to school and to appreciate the complex cultural and social history revealed through their pictures and stories. These stories provided an insight into the lives of the children and the things that were important to them. Through conversations around children's pictures and text, the teacher demonstrated interest, acceptance and valuing of their experiences and their writing attempts and supported children's identification and manipulation of the dynamic relationships among worlds. For example, when Jeva wrote ... and when I always sleep I have one picture of Dad or else I cry, the teacher encouraged her to talk about her feelings, to draw pictures, and write letters to her father in his absence.

The teacher interacted with children during writing sessions, scaffolding their writing attempts and creating potential for learning appropriate to their zone of proximal development (Vygotsky, 1978). She encouraged and facilitated opportunities for dialogue amongst the children when writing, as she valued the learning they gleaned from one another. Children actively learned from, or assisted, others as acknowledged experts. Zara, for example, relied heavily on Jeva and Grace to help her to write the words in the sentences she had composed.

Dialogue, in which children engaged before and as they wrote, helped them to plan and review their writing. For example, when Jeva declared at the start of a writing session, I'm going to write about Easter, Zara responded, Me too, I don't know yet what I'm going to say, I'm going to think about it. The children verbally planned and rehearsed what they were going to write in discussions with others, and were prompted by the picture they had drawn. The reviewing of writing served to cue them into where they were up to in transferring verbal text to written form, and was seen as a tactic to assist working memory. As they reviewed their progress, matching spoken word to written word, the children made changes 
or corrections to their writing that served as early editing. For example, Zara wrote: I went in my gudn. She paused and read her writing, erased the word gudn and re-wrote as gardn before adding / gro sm trees.

The knowledge and skills some children brought to the writing group gave them status. For example, Jeva's knowledge of individual letters and sounds and the automatic recall that she had developed prior to school gave her status in the writing group when others sought her assistance to help them to write words. This alphabetic knowledge, and her willingness to assist others, gained her entry and acceptance into the group. Bourdieu (1990) refers to the knowledge and the qualifications by which an individual gains entry to a particular setting as cultural capital.

The children's deference to Jeva's knowledge in relation to writing tasks and their actively seeking her assistance also gave her confidence when writing. The teacher may have established what was valued, but it was the children's decisions that conferred status to Jeva's knowledge. They measured established values against Jeva's demonstrated knowledge and took action to use it to achieve their own objectives.

\section{Active participation in Year 1}

The children's interactive behaviour contributed to the shaping of experiences and the classroom community in similar ways that actions and interactions shaped experiences and the environment at home and preschool, with one exception. Children's metacognitive awareness of their own thinking and learning processes displayed in Year 1, but not noted at preschool and at home, demonstrated the empowered way children engaged in acquiring knowledge and skills about literate and cultural practices valued at school. For example, when children declared the sounds they could identify in a word and the sounds they needed assistance with, they were displaying an awareness of their ability and the level of support required. Furthermore, children's ability to draw on knowledge, develop strategies and use tactics to make decisions that led to the application of behaviours appropriate to the environment in which they found themselves, contributed to the shaping of those environments.

\section{Discussion}

There is evidence throughout the study that children were actively acquiring the practices required to operate successfully in three worlds. Such a view does not present children as possessing a static repertoire of practices derived exclusively from home, nor does it portray children as passive recipients of culture passed on through school. Instead, children are seen as acquiring resources (knowledge, skills and dispositions) through active engagement and participation in activities at home, in preschool and in Year 1. It is this process of actively acquiring resources that is described in this study as world-building and contributes to the construction of a personal cultural identity.

The knowledge, skills and dispositions the children acquired in each of the three worlds combined to create conceptual and cultural resources that they utilised when operating in, and making sense of their worlds. The array of resources was constantly changing in size, shape, form and nature over time. For example, the knowledge of letters and sounds that Jeva had developed through recitation and writing at home, then practised in play at preschool, were refined and extended in her collaborative writing sessions in Year 1. In similar ways, the array of cultural knowledge and skills, and dispositional resources were expanded. The cultural diversity of environments meant a rich and increasing fund of resources that assisted children in negotiating encounters in all worlds.

In today's society, children's formative experiences are not limited to home. They interact socially, and spend extended periods in many cultural environments that influence their formative development. These may include child care, kindergarten, activity clubs, church and school. The sociocultural perspective taken in this study is that children's dispositional development (for example attitudes, values, interests and motivation) are derived from culture and socialisation beyond home and encompasses experiences in other environments. As a result, the system of dispositions that children developed was not constrained by their home environments. Instead, a rich system of dispositional resources was accrued in the three environments.

In this study, contextual change provoked in the children a search for effective behaviour. They recognised that a new context may need new ways of operating which sharpened their ability to read and respond to contextual cues, and they used strategies and tactics to identify accepted practices and achieve objectives. For example, as outlined earlier, it took Lia many weeks to determine how to successfully gain entry into group activities at preschool. She tried many tactics and strategies and brought the accumulated knowledge and awareness from each attempt to achieve success.

In attempting to make known their strong desire to belong and readiness to participate appropriately in activities, the children exhibited assimilation and accommodation adaptations akin to the mixing, transferring and borrowing that takes place in code-switching, a feature of crosslinguistic interaction (Palmer, 2009). These adaptations are worthy of more detailed research to determine their characteristics and whether they reflect a broader construct of cross-culture interaction that has been referred to as culture-switching, a term coined in this study. It represents the mixing, transferring, trying out, 
adapting, and experimenting with different worlds that children in this study undertook to determine appropriate practices at home and in the classroom.

\section{Conclusion}

This study described what literacy learning was like for five culturally diverse children. Within the constraints associated with the number of children studied and the gender, cultural backgrounds and school settings represented, it provides a rich description of literacy experiences in individual cases and identifies similarities and differences across experiences and between worlds. The interpretation of these situations using a sociocultural perspective may strike a chord in other researchers and teachers looking for patterns that help explain their own experiences, as well as events in their worlds. It may challenge former views of cultural learning styles as static, culturally different practices as deficient, children as passive, and adults as the only active agents capable of transmitting culture. In addition, the study establishes a sufficient evidential warrant for further investigation into the nature and dimensions of the world-building and culture-switching that seemingly underpins such experiences.

These findings, together with a consideration of the different beliefs and practices of the preschool and the Year 1 teacher, may provide direction for educators in determining how effective literacy teaching can take account of, and build on, family and community literacies. In particular, the three worlds' framework has direct implications for teachers when taking account of the cultural diversity in their classrooms. Teachers who use the framework may find it a useful instrument. By 'learning to ask and getting out of the way' (Pufall \& Unsworth, 2004, p. 8), they may encourage children to have their voices heard and to enact agency.

\section{References}

Anzaldua, G. (1987). Borderlands/La frontera: The new mestiza. San Francisco, CA: Spinsters/Aunt Lute.

Ashton, J., Woodrow, C., Johnston, C., Wangmann, J., Singh, L., \& James, T. (2008). Partnerships in learning: Linking early childhood services, families and schools for optimal development. Australian Journal of Early Childhood, 33(2), 10-17.

Bourdieu, P. (1990). In other words: Essays towards a reflexive sociology. Cambridge: Polity Press.

Chang, H. (1999). Re-examining the rhetoric of the "cultural border." Electronic Magazine of Multicultural Education, 1(1), $1-7$.

Charmaz, K. (2002). Qualitative interviewing and grounded theory analysis. In J. F. Gubrium \& J. A. Holstein (Eds), Handbook of interview research: Context and method (pp. 675-694). Thousand Oaks, CA: Sage Publications.
Freeman, L. \& Bochner, S. (2008). Bridging the gap: Improving literacy outcomes for Indigenous students. Australian Journal of Early Childhood, 33(4), 9-15.

Goldenberg, C. (1987). Low-income Hispanic parents' contributions to their first-grade children's word-recognition skills. Anthropology and Education Quarterly, 18, 149-179.

Greckhamer, T., \& Koro-Ljungber, M. (2005). The erosion of a method: Examples from grounded theory. International Journal of Qualitative Studies in Education, 18(6), 729-750.

Heath, S. (1982). Questioning at home and at school: A comparative study. In G. Spindler (Ed), Doing the ethnography of schooling. (pp. 103-127). Prospect Heights, IL: Waveland Press.

Laosa, L. M. (1980). Maternal teaching strategies in Chicano and Anglo-American families: The influence of culture and education on maternal behavior. Child Development, 51, 759-765.

Lareau, A. (2000). Home advantage: Social class and parental intervention in elementary education. Lanham, MD: Rowman \& Littlefield Publishers.

Lareau, A. (2003). Unequal childhoods: Class, race, and family life. Los Angeles, CA: University of California Press.

MacNaughton, G., Rolfe, S., \& Siraj-Blatchford, I. (2001). Doing early childhood research: International perspectives on theory and practice. Crows Nest, NSW: Allen \& Unwin.

Merriam, S. B. (1988). Case study research in education: A qualitative approach. San Francisco, CA: Jossey-Bass.

Palmer, D. (2009). Code-switching and symbolic power in a second-grade two-way classroom: A teacher's motivation system gone awry. Bilingual Research Journal, 32(1), 42-59.

Pufall, P. B., \& Unsworth, R.P. (2004). Rethinking childhood. New Brunswick: Rutgers University Press.

Purcell-Gates, V. (1993). Issues for family literacy research: Voices from the trenches. Language Arts, 70, 670-677.

Rogoff, B. (2003). The cultural nature of human development Oxford: Oxford University Press.

Rogoff, B., \& Angelillo, C. (2002). Investigating the coordinated functioning of multifaceted cultural practices in human development. Human Development, 45(4), 211-226.

Simpson, T. (2009). Early childhood education in Australia (Editorial). Australasian Journal of Early Childhood Education, 34(1), ii-V.

Strauss, A., \& Corbin, J. (1998). Basics of qualitative research: Techniques and procedures for developing grounded theory (Second edn). Thousand Oaks, CA: Sage Publications.

Taylor, D. (1983). Family literacy. Exeter, NH: Heinemann.

Vygotsky, L. (1978). Mind in society: The development of higher psychological processes. Cambridge MA: Harvard University Press. 


\section{More people in health and community services choose HESTA than any other fund}

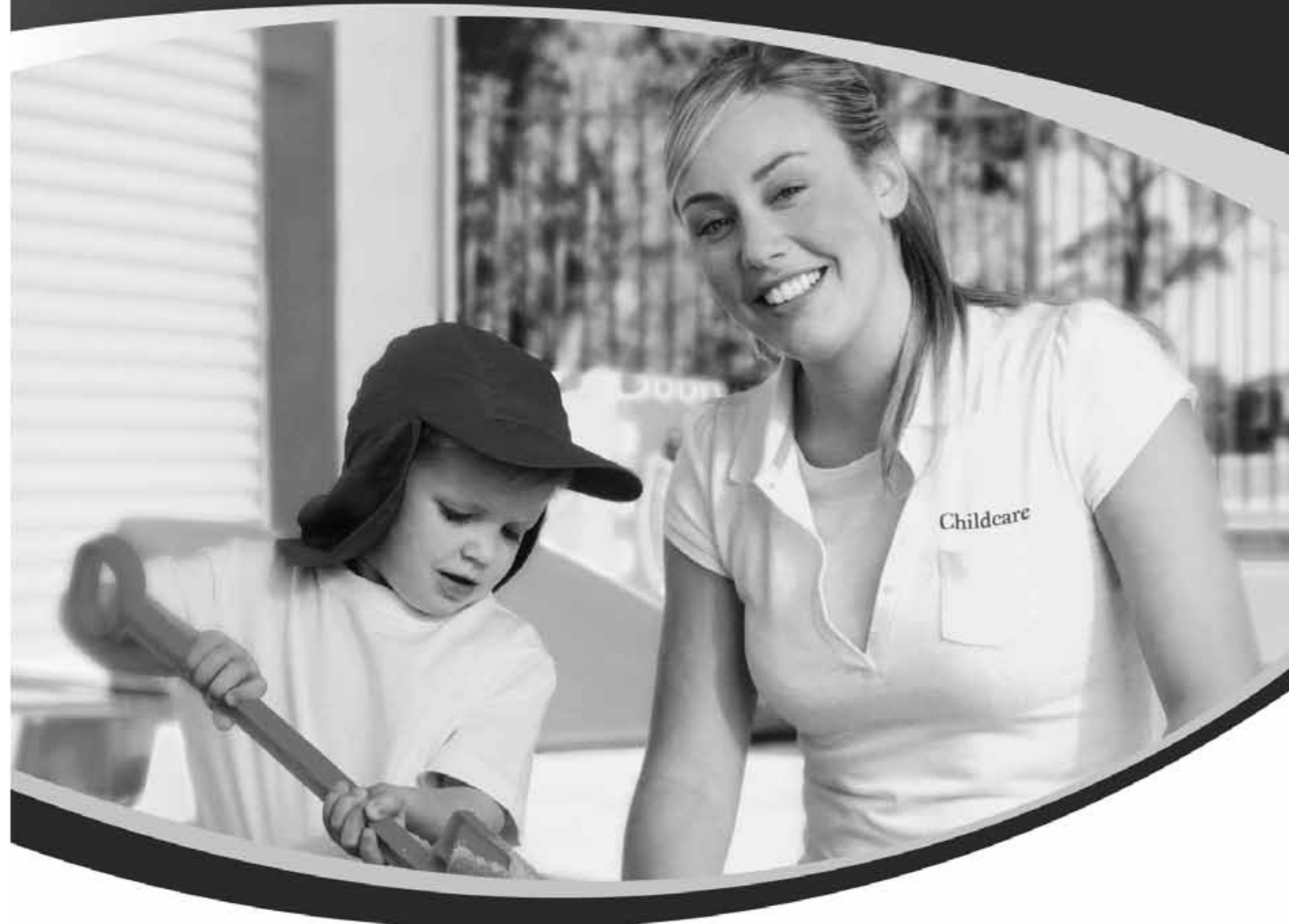

Your super fund can make a lifetime of difference

$\checkmark$ Run only to benefit members

$\checkmark$ No commissions

$\checkmark$ Low fees

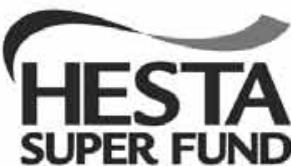

Your Health \& Community Services Industry Fund

hesta.com.au/super 


\section{WWW.earlychildhoodaustralia.org.au}

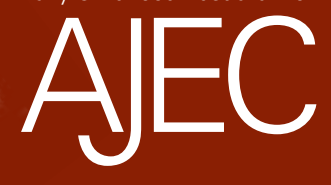

T: +61262421800

F: +61262421818

E: publishing@earlychildhood.org.au PO Box 86 Deakin West ACT 2600

ISSN 1836-9391

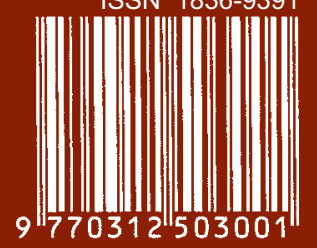

